\title{
Gene-Specific Sex Effects on Susceptibility to Infectious Diseases
}

\begin{abstract}
Marie Lipoldová ${ }^{1 *}$ and Peter Demant ${ }^{2}$
${ }^{1}$ Laboratory of Molecular and Cellular Immunology, Institute of Molecular Genetics of the Czech Academy of Sciences, Prague, Czechia, ${ }^{2}$ Department of Molecular and Cellular Biology, Roswell Park Comprehensive Cancer Center, Buffalo, NY, United States
\end{abstract}

Inflammation is an integral part of defense against most infectious diseases. These pathogen-induced immune responses are in very many instances strongly influenced by host's sex. As a consequence, sexual dimorphisms were observed in susceptibility to many infectious diseases. They are pathogen dose-dependent, and their outcomes depend on pathogen and even on its species or subspecies. Sex may differentially affect pathology of various organs and its influence is modified by interaction of host's hormonal status and genotype: sex chromosomes $X$ and $Y$, as well as autosomal genes. In this Mini Review we summarize the major influences of sex in human infections and subsequently focus on 22 autosomal genes/loci that modify in a sex-dependent way the response to infectious diseases in mouse models. These genes have been observed to influence susceptibility to viruses, bacteria, parasites, fungi and worms. Some sexdependent genes/loci affect susceptibility only in females or only in males, affect both sexes, but have stronger effect in one sex; still other genes were shown to affect the disease in both sexes, but with opposite direction of effect in females and males. The understanding of mechanisms of sex-dependent differences in the course of infectious diseases may be relevant for their personalized management.

Keywords: sex-bias, sex-dependent gene, mouse model, susceptibility to infection, sex influence, viruses, bacteria, parasites

\section{INTRODUCTION}

Sex plays an important role in immune response, including susceptibility to infectious diseases (1), outcome of vaccination (2-6) and response to treatment (7). Sex differences in susceptibility to infectious and inflammatory diseases are widespread - both in terms of number of pathogens and diseases they influence and in terms of the number of vertebrate and invertebrate species and genera where they were observed. In humans they were demonstrated in a number of diseases discussed in detail below and hence they form a significant but hitherto unexplained component of clinical interpatient heterogeneity. Their individual prediction and functional explanation may therefore significantly improve individual management of disease. A part of this phenomenon may be under genetic control, but there is presently little evidence for this in humans. However, there are extensive data from studies in mice that described 22 autosomal gene-loci controlling the sex differences in response to 12 infectious or inflammatory agents. We are presenting a comprehensive summary of this information, as it may help to proceed to clarification of the manifestations and mechanisms of sex differences in these pathologies. 
Sexual dimorphism takes place already in healthy individuals. In most cases, basal immune responses are higher in females than in males. It has been described that women have higher several immunology-related parameters than males: blood levels of mature B cell subsets, IgM-only B cells, proliferating and memory (CD45RA-) Treg cells, NK bright (CD56++CD16-) subsets (8), immunoglobulin $M$ (9), neutrophil and platelets (10), and higher CD4+/CD8+ ratio (11). TLR7 ligands induce higher IFN $\alpha$ production in woman peripheral blood lymphocytes (12). Neutrophils of men exhibit lower responses to cytokine stimulation and decreased ability to form neutrophil traps (13), whereas in women neutrophils were characterized by enhanced type I IFN pathway activity and enhanced proinflammatory responses (14). Male and female neutrophils differ also in bioenergetics. Metabolic assays of oxygen consumption rate (OCR), which is a key metric of mitochondrial function, and the extracellular acidification rate (ECAR), which approximates glycolytic activity in male and female neutrophils shown that OCR was higher in male than female neutrophils, whereas there were no differences in ECAR (14). As the immune cells differentiation and function crucially depend on mitochondrial bioenergetics $(15,16)$, sex differences in mitochondrial functions have a potential to modulate immune responses. Differences in immune responses have been observed also between males and females of other mammals (17-19), birds (20), reptiles (21), echinoderms (22) and insects (23). Such baseline differences can contribute to sex biases in response to pathogens (24,25 and see the next section) and to vaccination (2-6). Females usually have more efficient response to vaccination than males (25), but also develop more often adverse reactions to vaccination (4, 5). On the other hand, vaccination of healthy volunteers by Bacille Calmette-Guérin (BCG) led to enhanced cytokine responses to restimulation and reduced systemic inflammation. The effect was much stronger in men than in women (6).

\section{SEX BIASES IN HUMAN INFECTIONS}

\section{Viruses}

Male sex was associated with higher death rate in hepatitis A virushospitalized cases (24). Male sex was also a risk factor for hepatitis B virus $(\mathrm{HBV})$ and hepatitis $\mathrm{C}$ Virus $(\mathrm{HCV})$ prevalence and for development of hepatocellular carcinoma subsequent to $\mathrm{HBV}$ and/or HCV infection (25). Presence of virus stimulates inflammatory responses and appearance of reactive oxygen (ROS) and nitrogen species, which are described as leading cause of series of alterations that led to DNA damage (25). Estrogen may serve an inhibitory role in these processes by inhibiting inflammation, tumor progression and invasion and stimulating DNA repair (26), whereas androgen induced miR-216a stimulated tumorigenesis (27). The lower survival rate was observed among male patients infected with Ebola virus (28). The higher COVID-19 case mortality rate and increased severity of disease was described in males (29-31). Interestingly, gene encoding ACE2 (angiotensin-converting enzyme 2), which plays an essential role in cell entry of SARSCoV-2 (severe acute respiratory syndrome coronavirus 2) is localized on X chromosome (Xp22.2), thus females have double gene dose and can be potentially heterozygous compared to males who are definitely hemizygous. It has been speculated that together with $\mathrm{X}$ mosaicism it might favor women in counteracting the progression of the SARS-CoV-2 infection $(32,33)$. Prevalence of herpes simplex virus type 1 (HSV1) and type 2 (HSV2) in persons aged 14-49 in United States in the years 2015-2016 was higher in women than in men (34). Similarly, HSV1 in Europe was more often detected in women than in men (35). Sex differences in measles mortality were compared among 78 countries in years between 1950 and 1989. Regional variations showed excess female mortality of 3\% in Europe, 6.2\% in North America, 5.9\% in Far East Asia, $4.3 \%$ in Latin America, and $20.9 \%$ in the Middle East. The cumulative excess female mortality in comparison with males was small at age $0-4(+4.2 \%)$, larger at age $5-14(+10.9 \%)$, and peaks at ages $15-44(+42.6 \%)$ (36). The most probable explanation of these variations is the influence of estrogens (36). Several studies have shown that women are more susceptible to human immunodeficiency virus 1 (HIV-1) acquisition than men, as the male-to-female transmission is more efficient than female-to-male transmission (37, 38). Indeed, in Sub-Saharan Africa higher HIV prevalence is observed in women (39). However, in Europe, there are more newly detected HIV infections in males than in woman, because sex between men remains the predominant mode of HIV transmission reported in the EU (European Union)/EEA (European Economic Area) (40). Thus, socioeconomic factors most likely contribute to the sex biases in HIV/AIDS (Acquired Immune Deficiency Syndrome).

\section{Bacteria}

Sex differences have also been reported in bacterial infections. Analysis of 4742 randomly selected subjects, aged 12-64, from Northern Ireland shown that Helicobacter pylori infection was more common in males than in females (41). A retrospective seroepidemiologic survey of Chlamydia pneumoniae infection in patients in Beijing, China between 2008 and 2017 revealed that adult men had both a higher prevalence and higher levels of antibodies than women (42). Klebsiella spp. induced bacteremia was higher in males than in females in England, Wales, and Northern Ireland (43). $60 \%$ of patients hospitalized in the years 2005-2014 in USA with Lyme disease (infectious agent Borrelia burgdorferi) were men (44). On the other hand, reinfection with B. burgdorferi in individuals from Sweden that were initially diagnosed with erythema migrans and treated with antibiotics was much higher in women than in men (45). Incidence of tuberculosis that is caused by infection with Mycobacterium tuberculosis was described to be higher in men than in women (46), however a consistent female excess for tuberculosis at age 5-29 was observed (47). Listeria monocytogenes is a foodborne pathogen that is highly prevalent in pregnant woman, older adults and immunocompromised individuals. Incidence of listeriosis in the years 2008-2016 in USA was higher in males than in non-pregnant females (48). Socioeconomic factors highly influence the spread of syphilis: a sexually transmitted infection caused by Treponema pallidum. Sex differences in its incidence, prevalence and geographical variations have been well described. For example, the incidence of maternal syphilis is higher in low- to middle-income countries as compared to high-income countries where syphilis is more common among 
men who have sex with men. In Africa the spread of syphilis is also high in female sex workers $(49,50)$.

\section{Parasites}

Male sex is a risk factor for visceral leishmaniasis (51). Men were more susceptible to visceral infection caused by Leishmania donovani (52-54) and L. infantum (55-58). More variability was observed in studies of sex influence on cutaneous leishmaniasis. Some epidemiological studies revealed in male patients a higher incidence of cutaneous leishmaniasis caused by L. major and L. tropica $(59,60), L$. major only (61), and also by L. guyanensis (62). However, the study in Afghanistan found that females developed more lesions and scars after L. tropica infection (63) and other analyses reported no significant sex differences in registered cases of cutaneous leishmaniasis caused by L. tropica (64) and L. major (65). No sex bias was observed in intestinal schistosomiasis caused by Schistosoma mansoni in adults (66). Infection rates did not differ significantly among various age and sex groups infected with Schistosoma haematobium (67).

\section{Fungi}

Prior to the AIDS epidemics, cryptococcal disease, caused by Cryptococcus neoformans and Cryptococcus gattii was rather rare. It was reported in case series 2-3 times more frequently in men as in women (68). In the AIDS era, in the years 2000-2007 were in USA hospitalized 10077 patients with cryptococcal disease, 26\% were females. Males had a higher risk of a disease in both HIV-infected and uninfected cohorts. Age- and sex-adjusted death rates were almost threefold higher in males compared to females (69).

\section{Worms}

Females were found to be more predisposed to Ascaris lumbricoides infection than were males (70). Human neurocysticercosis results from the infection of the central nervous system with the larval stage of the intestinal tapeworm, Taenia solium. In Ecuador, the number of transitional cysts in brain was found to be higher in the female than in the male patients (71).

\section{VARIOUS INFLUENCES ON SEX EFFECTS}

Thus, differences in susceptibility and prevalence between males and females have been observed in many human infections. The extensive studies showed that some infectious diseases exhibit male $(24,25,28-31,41-43,52-58,68,69)$, the other female bias (34-36, 70, 71), but there are also epidemiological studies with contradictory results; some studies showing male and the other female bias or no sex bias in the same disease (37-40, 46, 47, 59-65). These disparities may be explained by the fact that the occurrence and susceptibility to infectious diseases is influenced by many factors such as presence of pathogen reservoir, presence and properties of pathogen transmission vector in case of vector borne diseases (72), as well as immune status, sex and hormonal status, age, nutrition, microbiome and genotype of the host (72-75) and multiple environmental factors, including climate changes (76). Susceptibility to many human diseases is modified by socio- cultural determinants, behavioral/lifestyle risk factors (50), prevalence of co-morbidities (48) and co-infection with several pathogens $(69,77)$.

\section{SEX-DEPENDENT RESPONSES REVEALED IN ANIMAL EXPERIMENTS}

Sex-dependent differences in response to pathogens could be more effectively analyzed in animal studies. Mouse experiments revealed important features of sex-dependent responses to infectious diseases: dose-dependence, pathogen and pathogen species-dependence, organ specificity and genetic modification.

\section{Dose-Dependent Sex Bias}

Dose-dependent sex bias was described in responses to viruses and bacteria. The response of the strain C57BL/6 infected intranasally with the mouse adapted influenza $\mathrm{A} / \mathrm{PR} 8 ; \mathrm{H} 1 \mathrm{~N} 1$ was sex-dependent when median infection dose $\left[10^{2}\right.$ or $10^{3} \mathrm{TCID}_{50}$ (tissue culture infectious dose)] were used and females exhibited higher mortality than males. The effect of infections with low $\left(10^{1} \mathrm{TCID}_{50}\right)$ or high $\left(10^{4}\right.$ or $10^{5} \mathrm{TCID}_{50}$ ) viral inoculi was sex independent (78). Dosedependent sex bias was observed also in the animal model of gramnegative sepsis. Wistar rats were injected intraperitoneally with bacteria Escherichia coli LPS in one of two doses: 1.5 or $15 \mathrm{mg} / \mathrm{kg}$. Day after the LPS injection, serum levels of endotoxin, corticosterone, alanine aminotransferase (ALT), and aspartate aminotransferase (AST) activity in the serum and morphological changes in the lung, liver, thymus, and spleen exhibited dose-dependent sex bias. Lowdose LPS led to the serum endotoxin level increase only in males and it was combined with a more pronounced inflammatory response in the lungs (characterized by infiltration of eosinophils and neutrophils) and thymus (characterized by presence of macrophages and dead lymphocytes) and an increase and decrease in ALT and AST activity, in males and females, respectively, without any changes in corticosterone level. High-dose LPS induced systemic inflammatory response syndrome (SIRS) comprises higher blood endotoxin levels in males than in females, lower the volume fraction index of the white pulp of the spleen of males, increase of apoptotic cells in thymus and decrease of corticosteroids in males only. Sex differences of pathological changes in the lungs and liver were not revealed (79). The observed dose-dependent sex differences might be largely caused by different dynamics of induction of different signaling pathways in males and females.

\section{Sex Differences Depend on Species and Sub-Species of Pathogen and on Genotype of the Host}

Sex bias in disease susceptibility and prevalence that is dependent on pathogen species is described in Sex Biases in Human Infections. Here we describe, that sex bias can depend also on pathogen sub-species. DBA/2 female mice are highly resistant and males susceptible to lesion development after infection with the parasite L. mexicana. On the contrary, although both female and male mice developed ulcerating lesions after infection with L. major, lesions healed in males, but not females (80). Sex 
differentially influenced also infection with $L$. tropica and L. major and the response was modified by genotype. Females of strains $\mathrm{BALB} / \mathrm{c}, \mathrm{CcS}-11, \mathrm{CcS}-16$ and $\mathrm{CcS}-20$ are more susceptible than males to development of skin lesions induced by L. tropica, whereas no sex bias was observed in strains STS, CcS-3, CcS-5, CcS-12 and CcS-18. On the other hand, infection by $L$. major induced larger skin lesions in males of strains CcS-3, CcS-5 and CcS-18, whereas no difference between males and females was observed in strains BALB/c, STS, CcS-11, CcS-12, CcS-16 and CcS-20 (81).

\section{Sex Affects Pathology of Various Organs Differently and Its Influence Is Modified by the Host Genotype}

Strains BALB/c and CcS-11 did not exhibit any sex influence on lesion size induced by L. major, but males of strain CcS-11 contained more parasites in spleens than females, and males of both strains had much higher parasite load in lymph nodes (82). Organ-dependent sex response was observed also in animal model of gram-negative sepsis (79). These phenomena might be explained by presence of different defense mechanisms in different tissues $(83,84)$, as well as by highly tissue-dependent sex-biases in expression of genes observed in intercross between strains $\mathrm{C} 57 \mathrm{BL} / 6$ and $\mathrm{C} 3 \mathrm{H} / \mathrm{HeJ}$ (85).

\section{MECHANISMS OF SEX-DEPENDENT RESPONSES}

The observed sex-differential responses to disease susceptibility may be explained by direct and indirect influence of sex hormones and non-hormonal sex-biasing influence of X and Y chromosomes. Sex steroid hormones (estrogen, testosterone and progesterone) influence response to infections by 1) direct effect on pathogen metabolism, growth, and expression of virulence factors. It was shown that physiological concentration of progesterone inhibited replication of Coxiella burnetii in JEG-3 cells (86), both testosterone and progesterone inhibited growth of Staphylococcus aureus (87). 2) by modification of immune response and physiology of the host. Effects on sex hormones on the host are exerted via sex hormone-receptor interactions. These receptors are present in cell nucleus and membrane (88) of non-immune and immune cells and tissues (88-91). Complexes of sex hormone-nuclear steroid receptor bind target DNA through hormone response elements to act as transcription factors (88). They can also bind to DNA-protein complexes and epigenetically modify cell functions $(90,91)$. Sex hormonereceptor complexes can exert their effects also through DNAindependent mechanisms, such as the activation of cytoplasmic signal transduction pathways (90). These interactions influence pro- and anti-inflammatory signaling pathways $(92,93)$. Indirect influences might include for example sex-dependent organ development (94) or influence of sex hormones on gut microbiota (95).

Non-hormonal sex-bias effects are mediated by genes localized on $\mathrm{X}$ and $\mathrm{Y}$ chromosomes $(1,96,97)$. The $\mathrm{X}$ chromosome carries a number of immune-related genes (96), such as toll-like receptor 7 (TLR7) and interleukin-1 receptor-associated kinase 1 (IRAK1), as well as a number of immune-associated microRNAs (96). X inactivation, or silencing of one $\mathrm{X}$ chromosome, in women would be expected to provide dosage compensation of X-linked genes, however certain regions of the $\mathrm{X}$ chromosome escape inactivation $(96,98)$. This can lead to higher transcription levels of specific genes that are involved in sex-specific responses $(96,99)$. The $Y$ chromosome also influences immune gene expression, regulation, and susceptibility to infections (97). For example, the Y chromosome mediates susceptibility to cocksackie virus independently of serum testosterone level (100). Genetic variation in chromosome $\mathrm{Y}$ regulates susceptibility to influenza $\mathrm{A}$ virus infection (101).

\section{MOUSE AUTOSOMAL GENES THAT CONTROL SEX-BIASED RESPONSES TO INFECTIONS}

Besides X- and Y-linked genes, there are also autosomal genes operating in sex-dependent manner. Sex-dependent autosomal genes modify response to viruses $(102-106)$, bacteria $(106,107)$, parasites (108-111), fungi (112) and worms (113) (Table 1, Figure 1). Three models were introduced to explain gene-sexinteractions (114). 1. "Environment specific effect": Sex dependent gene/loci affect susceptibility only in females $(102,104,107,111$, 112), or males (102-105, 108-110, 112, 113). 2. "A main effect" model for gene by environment (= sex) interaction. A disease can affect both sexes, but is more severe in one sex compared to the other $(106,107,111)$. 3. "A flip-flop" model of gene by environment interaction. Gene affects susceptibility in both sexes, but in different directions $(102,108)$.

\section{Viruses}

Theiler's murine encephalomyelitis virus-induced demyelination (TMEVD) is an animal model for virally triggered multiple sclerosis. QTLs (quantitative trait loci) Tmevd7 and Tmevd8 modify susceptibility to virus-induced demyelination in males only, Tmevd9 influences susceptibility to this disease in females and Tmevd6 affects susceptibility in both sexes, but has an opposite effect on males and females (102). Locus Rmp-4 (Resistance mousepox 4) modifies virus titer in spleen and liver as well as survival after infection with ectromelia virus (mousepox) (103). Two loci not named by authors NNI1 (not named influenza 1) and NNI2 control survival after infection with the mouse-adapted influenza $\mathrm{H} 3 \mathrm{~N} 2 / \mathrm{Hk} / 1 / 98$. NNI1 and NNI2 operate in females and males, respectively (104). Susceptibility to HSV1 is in males controlled by Hlr (herpes resistance locus) (105). Gene LRRK2 (leucine-rich repeat kinase2 ) is a $280 \mathrm{KDa}$, multi-domain protein that has dual catalytic and kinase activity as well as number of protein-protein interaction domains. Two major inflammatory pathways have been biochemically linked to LRRK2 action: TLR pathway and NFAT pathway (115). It is associated with Parkinson's disease, leprosy and Crohn's disease that are disorders with an important 
TABLE 1 | Autosomal genes and loci controlling sex-biased responses to infection in mouse.

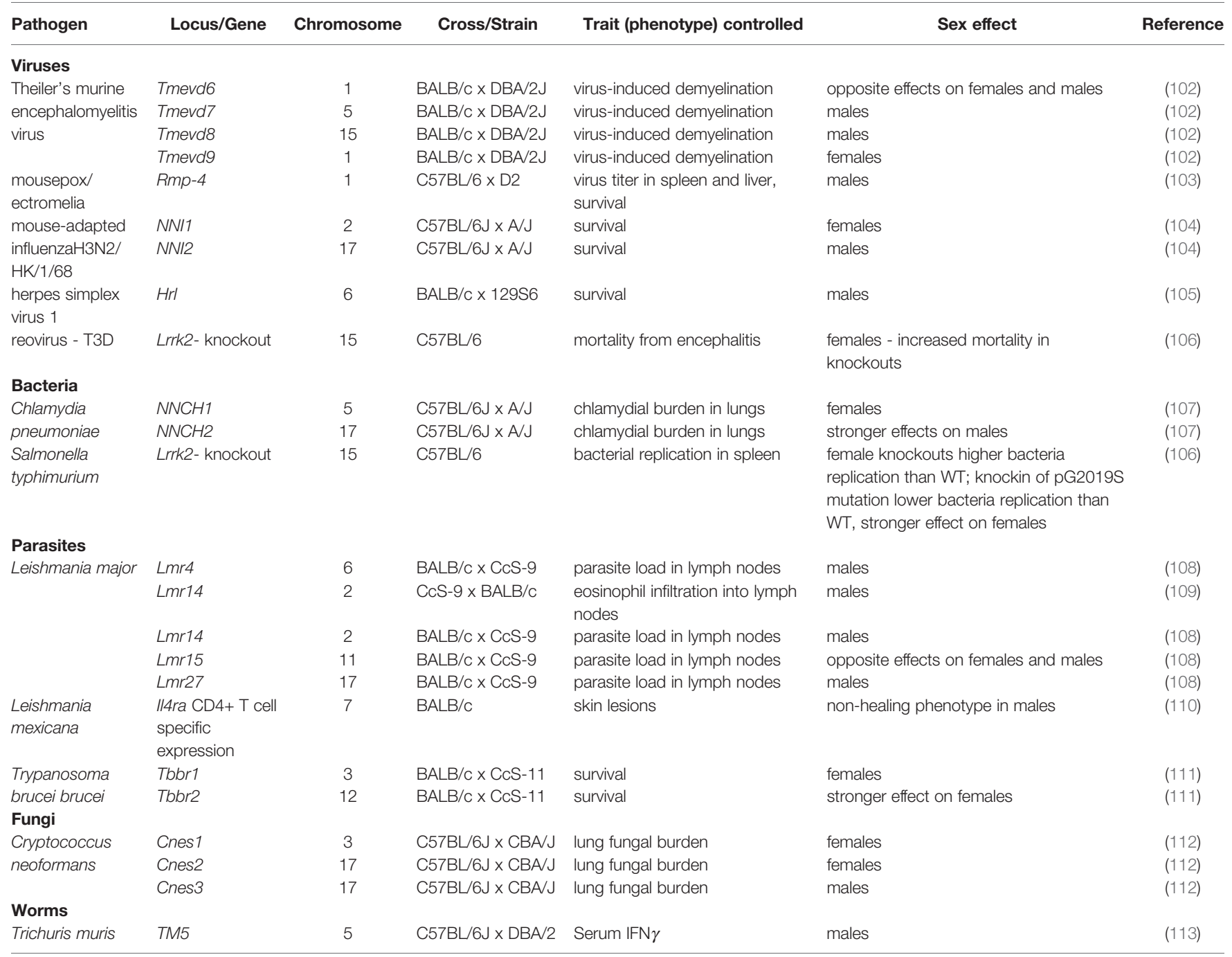

The Table summarizes position on chromosome, cross used to map certain locus or mouse genetic background, disease phenotype controlled and sex effect.

Cnes, Cryptococcus neoformans susceptibility; HIr, herpes resistance locus; Il4ra, interleukin 4 receptor alpha; Lmr, Leishmania major response; Lrrk2, leucine-rich repeat kinase-2;

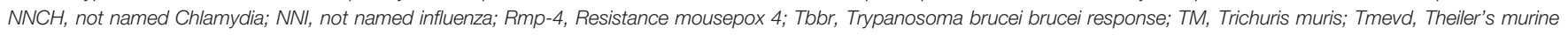
encephalomyelitis virus-induced demyelination.

inflammatory component. Shutinoski and co-workers tested hypothesis that Lrrk2 plays role also in infections with paramount inflammatory responses such as reovirus and Salmonella typhimurium (will be discussed in the next subsection). The increase of mortality caused by reovirus-induced encephalitis in Lrrk2-knockout mice in comparison with wild type animals was observed in female, but not in male mice (106).

\section{Bacteria}

Chlamydia pneumoniae causes a variety of respiratory diseases. Susceptibility to this pathogen was controlled by two sexdependent QTLs: NNCH1 (not named Chlamydia 1) and $\mathrm{NNCH}$. Effect of $\mathrm{NNCH1}$ was observed in females, whereas $\mathrm{NNCH} 2$ exerted stronger effect on males (107). Comparison of replication of S. typhimurium in spleens of wild type and Lrrk2knockout mice shown increased replication of bacteria in spleen of female knockouts. Knockin of Parkinson's Disease (PD)- linked p.G2019S Lrrk2 mutation led to lower pathogen burden in spleens. The effect was stronger in females (106).

\section{Parasites}

Sex-dependent QTLs operating in L. major infected mice are involved in control of pathogen load in lymph nodes (108) and infiltration of eosinophils into lymph nodes (109). Lmr4 (Leishmania major response) and Lmr27 control parasite load in lymph nodes in males, $L m r 14$ influences both parasite load in and eosinophil infiltration into lymph nodes in males and Lmr15 determines parasite load in lymph nodes in both sexes, but with opposite direction of effect $(108,109)$. Wild type BALB/c mice infected with L. mexicana develop non-healing, progressively growing skin lesions. Monitoring the course of infection with L. mexicana in $\mathrm{BALB} / \mathrm{c}$ mice lacking expression of IL- $4 \mathrm{R} \alpha$ (interleukin 4 receptor, alpha) in $\mathrm{CD}^{+} \mathrm{T}$ cells revealed that these mice developed small lesions, which subsequently healed in females, 

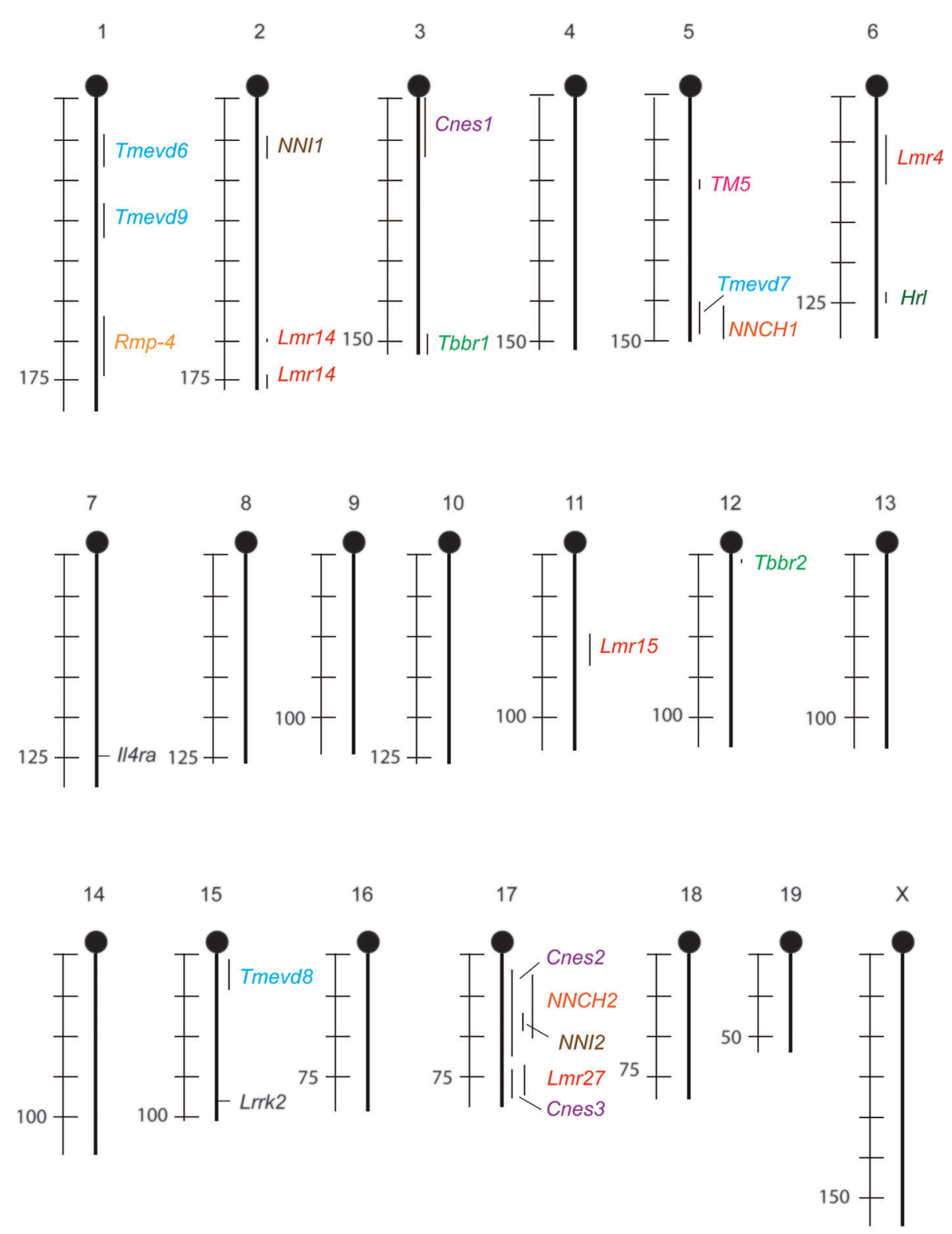

\section{Length of chromosomes is expressed in $\mathrm{Mb}$}

FIGURE 1 | Sex-dependent loci and genes that control susceptibility to infections in mouse and their overlaps. Cnes, Cryptococcus neoformans susceptibility; HIr, herpes resistance locus; I/4ra, interleukin 4 receptor alpha; Lmr, Leishmania major response; Lrrk2, leucine-rich repeat kinase-2; NNCH, not named Chlamydia; NNI, not named influenza; Rmp-4, Resistance mousepox 4; Tbbr, Trypanosoma brucei brucei response; TM, Trichuris muris; Tmevd, Theiler's murine encephalomyelitis virus-induced demyelination.

but persisted in males (110). Tbbr1 (Trypanosoma brucei brucei response 1) and Tbbr2 control survival after infection with T. $b$. brucei. Effect of Tbbr1 is visible only in females, Tbbr2 has stronger effect on females than on males (111).

\section{Fungi}

Cryptococcus neoformans is a fungal pathogen that causes pneumonia, meningitis and disseminated disease in immunocompromised host $(68,112)$. Fungal burden in lungs after infection with this pathogen was controlled by three sex-dependent QTLs. Cnes1 (Cryptococcus neoformans susceptibility 1) and Cnes2 operate in females, whereas effect of Cnes 3 is observed in males (112).

\section{Worms}

TM5 (Trichuris muris 5) is associated with IFN $\gamma$ production in serum of males infected with parasitic nematode T. muris (113). 


\section{Overlaps and Features of Sex-Dependent Loci}

Some sex-dependent loci co-localize (Figure 1). Locus Tmevd7 on chromosome 5 (102) overlaps with locus controlling susceptibility to Chlamydia (107). Cnes2 on proximal and central part of chromosome 17 (112) co-localizes with loci modifying susceptibility to Chlamydia (107) and influenza (104). Cnes3 on distal part on chromosome 17 (112) overlaps with Lmr27 (108). This suggests the presence either of clusters of functionally related genes, or of genes that are involved in controlling the response to several infections, similarly as Lrrk2 that controls response to reovirus and bacteria S. typhimurium (106).

Loci Lmr15 (108) and Tmevd6 (102) exhibit different effect on males and females (flip-flop model) (114) (Table 1). Both of them are localized on rather long chromosomal segments, thus we cannot exclude existence of two closely linked genes - one controlling susceptibility of males, the other females. However, it cannot be excluded that the opposite sex-dependent effects are controlled by one gene. Similar situation was described in humans. Polymorphism in rs2069885 (c.350 C>T) in IL9 (5q31.1) has an opposite effect on the risk of severe respiratory syncytial virus infection in boys and girls (116), as well as on Aspergillus fumigatus-induced allergic lung inflammation estimated as $\operatorname{IgE}$ level and IL9/IL9R mRNA ratio in lung expectorates in males and females suffering by cystic fibrosis (117). The inflammation is stimulated by IL-9 - IL-9R on mast cells - innate lymphoid cells - Th9 pathway (117). Sex influence might be exerted by interaction of IL-9 with IL-9R. IL9R is located in the pseudoautosomal regions 2 (PAR2) on Xq28 and Yq12 that behave as autosomes, recombine during meiosis and PAR regions on X escape silencing $(118,119)$.

\section{CONCLUSIONS AND PERSPECTIVE}

Sex differences in response to infections are frequent in human and form a considerable part of interpretation heterogeneity. The

\section{REFERENCES}

1. Klein SL, Flanagan KL. Sex Differences in Immune Responses. Nat Rev Immunol (2016) 16(10):626-38. doi: 10.1038/nri.2016.90

2. Troy JD, Hill HR, Ewell MG, Frey SE. Sex Difference in Immune Response to Vaccination: A Participant-Level Meta-Analysis of Randomized Trials of IMVAMUNE Smallpox Vaccine. Vaccine (2015) 33(41):5425-31. doi: 10.1016/j.vaccine.2015.08.032

3. Trevisan A, Giuliani A, Scapellato ML, Anticoli S, Carsetti R, Zaffina S, et al. Sex Disparity in Response to Hepatitis B Vaccine Related to the Age of Vaccination. Int J Environ Res Public Health (2020) 17(1):327. doi: 10.3390/ ijerph17010327

4. Fischinger S, Boudreau CM, Butler AL, Streeck H, Alter G. Sex Differences in Vaccine-Induced Humoral Immunity. Semin Immunopathol (2019) 41 (2):239-49. doi: 10.1007/s00281-018-0726-5

5. Fink AL, Klein SL. Sex and Gender Impact Immune Responses to Vaccines Among the Elderly. Physiol (Bethesda) (2015) 30(6):408-16. doi: 10.1152/ physiol.00035.2015

6. Koeken VA, de Bree LCJ, Mourits VP, Moorlag SJ, Walk J, Cirovic B, et al. BCG Vaccination in Humans Inhibits Systemic Inflammation in a Sex-Dependent Manner. J Clin Invest (2020) 130(10):5591-602. doi: 10.1172/JCI133935 genetic studies in mice revealed 22 genes/QTLs influencing these differences, suggesting a genetic heterogeneity of this phenomenon. The mechanisms of effects of these sex-specific mouse genes/QTLs are unknown, but may appear as a result of sex hormone regulation of the polymorphic genes underlying these QTLs or interaction between X- or Y-chromosome-linked genes (96-99). Some of the differences between females and males might be due to sex-specific genetic architecture, characterized by profound gene-sex interactions $(85,117,120$, 121). This would mean that some genes controlling response to infections might operate differently in the two sexes. The understanding of these sex- dependent responses could facilitate personalized medicine that would take into account sexual dimorphism in susceptibility to infectious diseases, outcome of vaccination and response to treatment.

\section{AUTHOR CONTRIBUTIONS}

ML and PD wrote the paper. Both authors contributed to the article and approved the submitted version.

\section{FUNDING}

This work was supported by the by the Czech Science Foundation (Grant GACR 16-22346S), the Czech Academy of Sciences (RVO 68378050) and the Ministry of Health (Grant NV19-05-00457).

\section{ACKNOWLEDGMENTS}

The authors thank Mrs. Helena Havelková for preparation of Figure 1.

7. Soldin OP, Mattison DR. Sex Differences in Pharmacokinetics and Pharmacodynamics. Clin Pharmacokinet (2009) 48(3):143-57. doi: 10.2165/00003088-200948030-00001

8. Aguirre-Gamboa R, Joosten I, Urbano PCM, van der Molen RG, van Rijssen E, van Cranenbroek B, et al. Differential Effects of Environmental and Genetic Factors on T and B Cell Immune Traits. Cell Rep (2016) 17(9):247487. doi: $10.1016 /$ j.celrep.2016.10.053

9. Butterworth M, McClellan B, Allansmith M. Influence of Sex in Immunoglobulin Levels. Nature (1967) 214(5094):1224-5. doi: 10.1038/ 2141224a0

10. Bain BJ. The Bone Marrow Aspirate of Healthy Subjects. Br J Haematol (1996) 94(1):206-9. doi: 10.1046/j.1365-2141.1996.d01-1786.x

11. Uppal SS, Verma S, Dhot PS. Normal Values of CD4 and CD8 Lymphocyte Subsets in Healthy Indian Adults and the Effects of Sex, Age, Ethnicity, and Smoking. Cytometry B Clin Cytom (2003) 52(1):32-6. doi: 10.1002/ cyto.b.10011

12. Berghöfer B, Frommer T, Haley G, Fink L, Bein G, Hackstein H. TLR7 Ligands Induce Higher IFN-Alpha Production in Females. J Immunol (2006) 177(4):2088-96. doi: 10.4049/jimmunol.177.4.2088

13. Blazkova J, Gupta S, Liu Y, Gaudilliere B, Ganio EA, Bolen CR, et al. Multicenter Systems Analysis of Human Blood Reveals Immature 
Neutrophils in Males and During Pregnancy. J Immunol (2017) 198 (6):2479-88. doi: 10.4049/jimmunol.1601855

14. Gupta S, Nakabo S, Blanco LP, O’Neil LJ, Wigerblad G, Goel RR, et al. Sex Differences in Neutrophil Biology Modulate Response to Type I Interferons and Immunometabolism. Proc Natl Acad Sci USA (2020) 117(28):16481-91. doi: $10.1073 /$ pnas.2003603117

15. Rambold AS, Pearce EL. Mitochondrial Dynamics at the Interface of Immune Cell Metabolism and Function. Trends Immunol (2018) 39(1):618. doi: 10.1016/j.it.2017.08.006

16. Nonnenmacher Y, Hiller K. Biochemistry of Proinflammatory Macrophage Activation. Cell Mol Life Sci (2018) 75(12):2093-109. doi: 10.1007/s00018018-2784-1

17. Scotland RS, Stables MJ, Madalli S, Watson P, Gilroy DW. Sex Differences in Resident Immune Cell Phenotype Underlie More Efficient Acute Inflammatory Responses in Female Mice. Blood (2011) 118(22):5918-27. doi: 10.1182/blood-2011-03-340281

18. Spitzer JA. Gender Differences in Some Host Defense Mechanisms. Lupus (1999) 8(5):380-3. doi: 10.1177/096120339900800510

19. Ćuruvija I, Stanojević S, Arsenović-Ranin N, Blagojević V, Dimitrijević M, Vidić-Danković B, et al. Sex Differences in Macrophage Functions in Middle-Aged Rats: Relevance of Estradiol Level and Macrophage Estrogen Receptor Expression. Inflammation (2017) 40(3):1087-101. doi: 10.1007/ s10753-017-0551-3

20. Valdebenito JO, Halimubieke N, Lendvai ÁZ, Figuerola J, Eichhorn G, Székely T. Seasonal Variation in Sex-Specific Immunity in Wild Birds. Sci Rep (2021) 11(1):1349. doi: 10.1038/s41598-020-80030-9

21. Mondal S, Rai U. Sexual Dimorphism in Phagocytic Activity of Wall Lizard's Splenic Macrophages and Its Control by Sex Steroids. Gen Comp Endocrinol (1999) 116(2):291-8. doi: 10.1006/gcen.1999.7370

22. Arizza V, Vazzana M, Schillaci D, Russo D, Giaramita FT, Parrinello N. Gender Differences in the Immune System Activities of Sea Urchin Paracentrotus Lividus. Comp Biochem Physiol A Mol Integr Physiol (2013) 164(3):447-55. doi: 10.1016/j.cbpa.2012.11.021

23. Belmonte RL, Corbally MK, Duneau DF, Regan JC. Sexual Dimorphisms in Innate Immunity and Responses to Infection in Drosophila Melanogaster. Front Immunol (2020) 10:3075. doi: 10.3389/fimmu.2019.03075

24. Chen CM, Chen SC, Yang HY, Yang ST, Wang CM. Hospitalization and Mortality Due to Hepatitis A in Taiwan: A 15-Year Nationwide Cohort Study. J Viral Hepat (2016) 23(11):940-5. doi: 10.1111/jvh.12564

25. Ruggieri A, Barbati C, Malorni W. Cellular and Molecular Mechanisms Involved in Hepatocellular Carcinoma Gender Disparity. Int J Cancer (2010) 127(3):499-504. doi: 10.1002/ijc.25298

26. Li Y, Xu A, Jia S, Huang J. Recent Advances in the Molecular Mechanism of Sex Disparity in Hepatocellular Carcinoma. Oncol Lett (2019) 17(5):4222-8. doi: 10.3892/ol.2019.10127

27. Chen PJ, Yeh SH, Liu WH, Lin CC, Huang HC, Chen CL, et al. Androgen Pathway Stimulates microRNA-216a Transcription to Suppress the Tumor Suppressor in Lung Cancer-1 Gene in Early Hepatocarcinogenesis. Hepatology (2012) 56(2):632-43. doi: 10.1002/hep.25695

28. WHO Ebola Response Team, Agua-Agum J, Ariyarajah A, Blake IM, Cori A, Donnelly CA, et al. Ebola Virus Disease Among Male and Female Persons in West Africa. N Engl J Med (2016) 374(1):96-8. doi: 10.1056/NEJMc1510305

29. Haitao T, Vermunt JV, Abeykoon J, Ghamrawi R, Gunaratne M, Jayachandran M, et al. COVID-19 and Sex Differences: Mechanisms and >Biomarkers. Mayo Clin Proc (2020) 95(10):2189-203. doi: 10.1016/j.mayocp. 2020.07.024

30. Alwani M, Yassin A, Al-Zoubi RM, Aboumarzouk OM, Nettleship J, Kelly D, et al. Sex-Based Differences in Severity and Mortality in COVID-19. Rev Med Virol (2021) 1:1-11. doi: 10.1002/rmv.2223

31. Jin S, An H, Zhou T, Li T, Xie M, Chen S, et al. Sex- and Age-Specific Clinical and Immunological Features of Coronavirus Disease 2019. PloS Pathog (2021) 17(3):e1009420. doi: 10.1371/journal.ppat.1009420

32. Gemmati D, Bramanti B, Serino ML, Secchiero P, Zauli G, Tisato V. COVID-19 and Individual Genetic Susceptibility/Receptivity: Role of ACE1/ACE2 Genes, Immunity, Inflammation and Coagulation. Might the Double X-Chromosome in Females be Protective Against SARS-CoV-2 Compared to the Single X-Chromosome in Males? Int J Mol Sci (2020) 21 (10):3474. doi: 10.3390/ijms21103474
33. Devaux CA, Rolain JM, Raoult D. ACE2 Receptor Polymorphism: Susceptibility to SARS-CoV-2, Hypertension, Multi-Organ Failure, and COVID-19 Disease Outcome. J Microbiol Immunol Infect (2020) 53 (3):425-35. doi: 10.1016/j.jmii.2020.04.015

34. McQuillan G, Kruszon-Moran D, Flagg EW, Paulose-Ram R. Prevalence of Herpes Simplex Virus Type 1 and Type 2 in Persons Aged 14-49: United States, 2015-2016. NCHS Data Brief (2018) 304):1-8.

35. Yousuf W, Ibrahim H, Harfouche M, Abu Hijleh F, Abu-Raddad L. Herpes Simplex Virus Type 1 in Europe: Systematic Review, Meta-Analyses and Meta-Regressions. BMJ Glob Health (2020) 5(7):e002388. doi: 10.1136/ bmjgh-2020-002388

36. Garenne M. Sex Differences in Measles Mortality: A World Review. Int $J$ Epidemiol (1994) 23(3):632-42. doi: 10.1093/ije/23.3.632

37. Nicolosi A, Corrêa Leite ML, Musicco M, Arici C, Gavazzeni G, Lazzarin A. The Efficiency of Male-to-Female and Female-to-Male Sexual Transmission of the Human Immunodeficiency Virus: A Study of 730 Stable Couples. Italian Study Group on HIV Heterosexual Transmission. Epidemiology (1994) 5(6):570-5. doi: 10.1097/00001648-199411000-00003

38. Griesbeck M, Scully E, Altfeld M. Sex and Gender Differences in HIV-1 Infection. Clin Sci (Lond) (2016) 130(16):1435-51. doi: 10.1042/CS20160112

39. Hegdahl HK, Fylkesnes KM, Sandøy IF. Sex Differences in HIV Prevalence Persist Over Time: Evidence From 18 Countries in Sub-Saharan Africa. PloS One (2016) 11(2):e0148502. doi: 10.1371/journal.pone.0148502

40. European Centre for Disease Prevention and Control/WHO, Regional Office for Europe. HIV/AIDS Surveillance in Europe 2019 - 2018 Data (2019). Stockholm: ECDC. Available at: https://www.ecdc.europa.eu/en/ publications-data/hivaids-surveillance-europe-2019-2018-data (Accessed July 29, 2021).

41. Murray LJ, McCrum EE, Evans AE, Bamford KB. Epidemiology of Helicobacter Pylori Infection Among 4742 Randomly Selected Subjects From Northern Ireland. Int J Epidemiol (1997) 26(4):880-7. doi: 10.1093/ ije/26.4.880

42. Cui J, Yan W, Xie H, Xu S, Wang Q, Zhang W, et al. A Retrospective Seroepidemiologic Survey of Chlamydia Pneumoniae Infection in Patients in Beijing Between 2008 and 2017. PloS One (2018) 13(11):e0206995. doi: 10.1371/journal.pone.0206995

43. Public Health England Laboratory Surveillance of Klebsiella Ssp. Bacteraemia in England, Wales and Northern Ireland: 2018. Health Prot Rep (2020) 14:1-18.

44. Schwartz AM, Shankar MB, Kugeler KJ, Max RJ, Hinckley AF, Meltzer MI, et al. Epidemiology and Cost of Lyme Disease-Related Hospitalizations Among Patients With Employer-Sponsored Health Insurance-United States, 2005-2014. Zoonoses Public Health (2020) 67(4):407-15. doi: 10.1111/ zph.12699

45. Jarefors S, Bennet L, You E, Forsberg P, Ekerfelt C, Berglund J, et al. Lyme Borreliosis Reinfection: Might It Be Explained by a Gender Difference in Immune Response? Immunology (2006) 118(2):224-32. doi: 10.1111/j.13652567.2006.02360.x

46. Hertz D, Schneider B. Sex Differences in Tuberculosis. Semin Immunopathol (2019) 41(2):225-37. doi: 10.1007/s00281-018-0725-6

47. Preston SH. Mortality Patterns in National Populations. 1st Edition. HH Winsborough, editor. New York: Academic Press (1976).

48. Pohl AM, Pouillot R, Bazaco MC, Wolpert BJ, Healy JM, Bruce BB, et al. Differences Among Incidence Rates of Invasive Listeriosis in the U.S. FoodNet Population by Age, Sex, Race/Ethnicity, and Pregnancy Status, 2008-2016. Foodborne Pathog Dis (2019) 16(4):290-7. doi: 10.1089/ fpd.2018.2548

49. Bremer V, Marcus U, Hamouda O. Syphilis on the Rise Again in Germanyresults From Surveillance Data for 2011. Euro Surveill (2012) 17(29):20222.

50. Peeling RW, Mabey D, Kamb ML, Chen XS, Radolf JD, Benzaken AS. Syphilis. Nat Rev Dis Primers (2017) 3:17073. doi: 10.1038/nrdp.2017.73

51. Cloots K, Burza S, Malaviya P, Hasker E, Kansal S, Mollett G, et al. Male Predominance in Reported Visceral Leishmaniasis Cases: Nature or Nurture? A Comparison of Population-Based With Health FacilityReported Data. PloS Negl Trop Dis (2020) 14(1):e0007995. doi: 10.1371/ journal.pntd.0007995

52. Rijal S, Uranw S, Chappuis F, Picado A, Khanal B, Paudel IS, et al. Epidemiology of Leishmania Donovani Infection in High-Transmission 
Foci in Nepal. Trop Med Int Heal (2010) 15:21-8. doi: 10.1111/j.13653156.2010.02518.x

53. Jervis S, Chapman LAC, Dwivedi S, Karthick M, Das A, Le Rutte EA, et al. Variations in Visceral Leishmaniasis Burden, Mortality and the Pathway to Care Within Bihar, India. Parasit Vectors (2017) 10(1):601. doi: 10.1186/ s13071-017-2530-9

54. Wondimeneh Y, Takele Y, Atnafu A, Ferede G, Muluye D. Trend Analysis of Visceral Leishmaniasis at Addis Zemen Health Center, Northwest Ethiopia. BioMed Res Int (2014) 2014:545393. doi: 10.1155/2014/545393

55. Harizanov R, Rainova I, Tzvetkova N, Kaftandjiev I, Bikov I, Mikov O. Geographical Distribution and Epidemiological Characteristics of Visceral Leishmaniasis in Bulgaria, 1988 to 2012. Eurosurveillance (2013) 18:20531. doi: 10.2807/1560-7917.ES2013.18.29.20531

56. Lachaud L, Dedet JP, Marty P, Faraut F, Buffet P, Gangneux JP, et al. Surveillance of Leishmaniases in France, 1999 to 2012. Eurosurveillance (2013) 18:20534. doi: 10.2807/1560-7917.ES2013.18.29.20534

57. Herrador Z, Gherasim A, Jimenez BC, Granados M, San Martín JV, Aparicio P. Epidemiological Changes in Leishmaniasis in Spain According to Hospitalization-Based Records, 1997-2011: Raising Awareness Towards Leishmaniasis in Non-HIV Patients. PloS Negl Trop Dis (2015) 9: e0003594. doi: 10.1371/journal.pntd.0003594

58. Rodriguez NE, Lima ID, Dixit UG, Turcotte EA, Lockard RD, Batra-Sharma $\mathrm{H}$, et al. Epidemiological and Experimental Evidence for Sex-Dependent Differences in the Outcome of Leishmania Infantum Infection. Am J Trop Med Hyg (2018) 98:142-5. doi: 10.4269/ajtmh.17-0563

59. Gandacu D, Glazer Y, Anis E, Karakis I, Warshavsky B, Slater P, et al. Resurgence of Cutaneous Leishmaniasis in Israel, 2001-2012. Emerg Infect Dis (2014) 20:1605-11. doi: 10.3201/eid2010.140182

60. Spotin A, Rouhani S, Parvizi P. The Associations of Leishmania Major and Leishmania Tropica Aspects by Focusing Their Morphological and Molecular Features on Clinical Appearances in Khuzestan Province, Iran. BioMed Res Int (2014) 2014:913510. doi: 10.1155/2014/913510

61. Collis S, El-Safi S, Bhattacharyya T, Hammad A, Den Boer M, Lee H, et al. Epidemiological and Molecular and Molecular Investigation of Resurgent Cutaneous Leishmaniasis in Sudan. Int J Infect Dis (2019) 88:14-20. doi: 10.1016/j.ijid.2019.08.018

62. Soares L, Abad-Franch F, Ferraz G. Epidemiology of Cutaneous Leishmaniasis in Central Amazonia: A Comparison of Sex-Biased Incidence Among Rural Settlers and Field Biologists. Trop Med Int Heal (2014) 19:988-95. doi: 10.1111/tmi.12337

63. Reithinger R, Mohsen M, Aadil K, Sidiqi M, Erasmus P, Coleman PG. Anthroponotic Cutaneous Leishmaniasis, Kabul, Afghanistan. Emerg Infect Dis (2003) 9:727-9. doi: 10.3201/eid0906.030026

64. Layegh P, Moghiman T, Ahmadian Hoseini SA. Children and Cutaneous Leishmaniasis: A Clinical Report and Review. J Infect Dev Ctries (2013) 7:614-7. doi: $10.3855 /$ jidc.2939

65. Bettaieb J, Toumi A, Chlif S, Chelghaf B, Boukthir A, Gharbi A, et al. Prevalence and Determinants of Leishmania Major Infection in Emerging and Old Foci in Tunisia. Parasit Vectors (2014) 7:386. doi: 10.1186/17563305-7-386

66. Bakuza JS, Denwood MJ, Nkwengulila G, Mable BK. Estimating the Prevalence and Intensity of Schistosoma Mansoni Infection Among Rural Communities in Western Tanzania: The Influence of Sampling Strategy and Statistical Approach. PloS Negl Trop Dis (2017) 11(9):e0005937. doi: 10.1371/journal.pntd.0005937

67. Hazza YA, Arfaa F, Haggar M. Studies on Schistosomiasis in Taiz Province, Yemen Arab Republic. Am J Trop Med Hyg (1983) 32(5):1023-8. doi: 10.4269/ ajtmh.1983.32.1023

68. Hajjeh RA, Brandt ME, Pinner RW. Emergence of Cryptococcal Disease: Epidemiologic Perspectives 100 Years After Its Discovery. Epidemiol Rev (1995) 17(2):303-20. doi: 10.1093/oxfordjournals.epirev.a036195

69. Shaheen AA, Somayaji R, Myers R, Mody CH. Epidemiology and Trends of Cryptococcosis in the United States From 2000 to 2007: A Population-Based Study. Int J STD AIDS (2018) 29(5):453-60. doi: 10.1177/0956462417732649

70. Wright JE, Werkman M, Dunn JC, Anderson RM. Current Epidemiological Evidence for Predisposition to High or Low Intensity Human Helminth Infection: A Systematic Review. Parasit Vectors (2018) 11(1):65. doi: $10.1186 / s 13071-018-2656-4$
71. Kelvin EA, Carpio A, Bagiella E, Leslie D, Leon P, Andrews H, et al. Ecuadorian Neurocysticercosis Group. The Association of Host Age and Gender With Inflammation Around Neurocysticercosis Cysts. Ann Trop Med Parasitol (2009) 103(6):487-99. doi: 10.1179/000349809X12459740922291

72. Krayem I, Lipoldová M. Role of Host Genetics and Cytokines in Leishmania Infection. Cytokine (2021) 147:155244. doi: 10.1016/j.cyto.2020.155244

73. Lipoldová M, Demant P. Genetic Susceptibility to Infectious Disease: Lessons From Mouse Models of Leishmaniasis. Nat Rev Genet (2006) 7:294-305. doi: 10.1038/nrg1832

74. Chapman SJ, Hill AV. Human Genetic Susceptibility to Infectious Disease. Nat Rev Genet (2012) 13(3):175-88. doi: 10.1038/nrg3114

75. Kerner G, Patin E, Quintana-Murci L. New Insights Into Human Immunity From Ancient Genomics. Curr Opin Immunol (2021) 72:116-25. doi: 10.1016/j.coi.2021.04.006

76. Sorensen C, Murray V, Lemery J, Balbus J. Climate Change and Women's Health: Impacts and Policy Directions. PloS Med (2018) 15(7):e1002603. doi: 10.1371/journal.pmed.1002603

77. Tchuem Tchuenté LA, Behnke JM, Gilbert FS, Southgate VR, Vercruysse J. Polyparasitism With Schistosoma Haematobium and Soil-Transmitted Helminth Infections Among School Children in Loum, Cameroon. Trop Med Int Health (2003) 8(11):975-86. doi: 10.1046/j.1360-2276.2003.01120.x

78. Lorenzo ME, Hodgson A, Robinson DP, Kaplan JB, Pekosz A, Klein SL. Antibody Responses and Cross Protection Against Lethal Influenza A Viruses Differ Between the Sexes in C57BL/6 Mice. Vaccine (2011) 29 (49):9246-55. doi: 10.1016/j.vaccine.2011.09.110

79. Kosyreva AM, Makarova OV, Kakturskiy LV, Mikhailova LP, Boltovskaya MN, Rogov KA. Sex Differences of Inflammation in Target Organs, Induced by Intraperitoneal Injection of Lipopolysaccharide, Depend on Its Dose. J Inflamm Res (2018) 11:431-45. doi: 10.2147/JIR.S178288

80. Alexander J. Sex Differences and Cross-Immunity in DBA/2 Mice Infected With L. Mexicana and L. Major. Parasitology (1988) 96(Pt 2):297-302. doi: 10.1017/s0031182000058303

81. Kobets T, Havelková H, Grekov I, Volkova V, Vojtišsová J, Slapničková M, et al. Genetics of Host Response to Leishmania Tropica in Mice - Different Control of Skin Pathology, Chemokine Reaction, and Invasion Into Spleen and Liver. PloS Negl Trop Dis (2012) 6:e1667. doi: 10.1371/journal.pntd.0001667

82. Kurey I, Kobets T, Havelková H, Slapnicková M, Quan L, Trtková K, et al. Distinct Genetic Control of Parasite Elimination, Dissemination, and Disease After Leishmania Major Infection. Immunogenetics (2009) 61 (9):619-33. doi: 10.1007/s00251-009-0392-9

83. Stenger S, Donhauser N, Thüring H, Röllinghoff M, Bogdan C. Reactivation of Latent Leishmaniasis by Inhibition of Inducible Nitric Oxide Synthase. J Exp Med (1996) 183(4):1501-14. doi: 10.1084/jem.183.4.1501

84. Blos M, Schleicher U, Soares Rocha FJ, Meissner U, Röllinghoff M, Bogdan C. Organ-Specific and Stage-Dependent Control of Leishmania Major Infection by Inducible Nitric Oxide Synthase and Phagocyte NADPH Oxidase. Eur J Immunol (2003) 33(5):1224-34. doi: 10.1002/eji.200323825

85. Yang X, Schadt EE, Wang S, Wang H, Arnold AP, Ingram-Drake L, et al. Tissue-Specific Expression and Regulation of Sexually Dimorphic Genes in Mice. Genome Res (2006) 16(8):995-1004. doi: 10.1101/gr.5217506

86. Howard ZP, Omsland A. Selective Inhibition of Coxiella Burnetii Replication by the Steroid Hormone Progesterone. Infect Immun (2020) 88(12):e0089419. doi: 10.1128/IAI.00894-19

87. Fitzgerald TJ, Yotis WW. Mechanism of Action of the Gonadal Steroids Producing Diminution of Growth of Staphylococcus Aureus. J Appl Bacteriol (1973) 36(4):707-21. doi: 10.1111/j.1365-2672.1973.tb04156.x

88. Wierman ME. Sex Steroid Effects at Target Tissues: Mechanisms of Action. Adv Physiol Educ (2007) 31(1):26-33. doi: 10.1152/advan.00086.2006

89. Hammes SR, Levin ER. Extranuclear Steroid Receptors: Nature and Actions. Endocr Rev (2007) 28(7):726-41. doi: 10.1210/er.2007-0022

90. Brown MA, Su MA. An Inconvenient Variable: Sex Hormones and Their Impact on T Cell Responses. J Immunol (2019) 202(7):1927-33. doi: 10.4049/jimmunol.1801403

91. Shepherd R, Cheung AS, Pang K, Saffery R, Novakovic B. Sexual Dimorphism in Innate Immunity: The Role of Sex Hormones and Epigenetics. Front Immunol (2021) 11:604000. doi: 10.3389/fimmu.2020.604000

92. Kovats S. Estrogen Receptors Regulate Innate Immune Cells and Signaling Pathways. Cell Immunol (2015) 294(2):63-9. doi: 10.1016/j.cellimm.2015.01.018 
93. Robinson DP, Lorenzo ME, Jian W, Klein SL. Elevated 17beta-Estradiol Protects Females From Influenza A Virus Pathogenesis by Suppressing Inflammatory Responses. PloS Pathog (2011) 7(7):e1002149. doi: 10.1371/ journal.ppat.1002149

94. White V, Jawerbaum A, Mazzucco MB, Gauster M, Desoye G, Hiden U. IGF2 Stimulates Fetal Growth in a Sex- and Organ-Dependent Manner. Pediatr Res (2018) 83(1-1):183-9. doi: 10.1038/pr.2017.221

95. Yoon K, Kim N. Roles of Sex Hormones and Gender in the Gut Microbiota. J Neurogastroenterol Motil (2021) 27(3):314-25. doi: 10.5056/jnm20208

96. Schurz H, Salie M, Tromp G, Hoal EG, Kinnear CJ, Möller M. The X Chromosome and Sex-Specific Effects in Infectious Disease Susceptibility. Hum Genomics (2019) 13(1):2. doi: 10.1186/s40246-018-0185-z

97. Case LK, Teuscher C. Y Genetic Variation and Phenotypic Diversity in Health and Disease. Biol Sex Differ (2015) 6:6. doi: 10.1186/s13293-015-0024-z

98. Balaton BP, Brown CJ. Escape Artists of the X Chromosome. Trends Genet (2016) 32(6):348-59. doi: 10.1016/j.tig.2016.03.007

99. Karnam G, Rygiel TP, Raaben M, Grinwis GC, Coenjaerts FE, Ressing ME, et al. CD200 Receptor Controls Sex-Specific TLR7 Responses to Viral Infection. PloS Pathog (2012) 8(5):e1002710. doi: 10.1371/journal.ppat.1002710

100. Case LK, Toussaint L, Moussawi M, Roberts B, Saligrama N, Brossay L, et al. Chromosome Y Regulates Survival Following Murine Coxsackievirus B3 Infection. G3 (Bethesda) (2012) 2(1):115-21. doi: 10.1534/g3.111.001610

101. Krementsov DN, Case LK, Dienz O, Raza A, Fang Q, Ather JL, et al. Genetic Variation in Chromosome Y Regulates Susceptibility to Influenza A Virus Infection. Proc Natl Acad Sci USA (2017) 114(13):3491-6. doi: 10.1073/ pnas.1620889114

102. Butterfield RJ, Roper RJ, Rhein DM, Melvold RW, Haynes L, Ma RZ, et al. Sex-Specific Quantitative Trait Loci Govern Susceptibility to Theiler's Murine Encephalomyelitis Virus-Induced Demyelination. Genetics (2003) 163:1041-6. doi: 10.1093/genetics/163.3.1041

103. Brownstein DG, Gras L. Chromosome Mapping of Rmp-4, A GonadDependent Gene Encoding Host Resistance to Mousepox. J Virol (1995) 69(11):6958-64. doi: 10.1128/JVI.69.11.6958-6964.1995

104. Boivin GA, Pothlichet J, Skamene E, Brown EG, Loredo-Osti JC, Sladek R, et al. Mapping of Clinical and Expression Quantitative Trait Loci in a SexDependent Effect of Host Susceptibility to Mouse-Adapted Influenza H3N2/ HK/1/68. J Immunol (2012) 188:3949-60. doi: 10.4049/jimmunol.1103320

105. Lundberg P, Welander P, Openshaw H, Nalbandian C, Edwards C, Moldawer L, et al. A Locus on Mouse Chromosome 6 That Determines Resistance to Herpes Simplex Virus Also Influences Reactivation, While an Unlinked Locus Augments Resistance of Female Mice. J Virol (2003) 77 (21):11661-73. doi: 10.1128/jvi.77.21.11661-11673.2003

106. Shutinoski B, Hakimi M, Harmsen IE, Lunn M, Rocha J, Lengacher N, et al. Lrrk2 Alleles Modulate Inflammation During Microbial Infection of Mice in a Sex-Dependent Manner. Sci Transl Med (2019) 11(511):eaas9292. doi: 10.1126/scitranslmed.aas9292

107. Min-Oo G, Lindqvist L, Vaglenov A, Wang C, Fortin P, Li Y, et al. Genetic Control of Susceptibility to Pulmonary Infection With Chlamydia Pneumoniae in the Mouse. Genes Immun (2008) 9:383-8. doi: 10.1038/sj.gene.6364450

108. Kobets T, Čepičková M, Volkova V, Sohrabi Y, Havelková H, Svobodová M, et al. Novel Loci Controlling Parasite Load in Organs of Mice Infected With Leishmania Major, Their Interactions and Sex Influence. Front Immunol (2019) 10:1083. doi: 10.3389/fimmu.2019.01083

109. Slapničková M, Volkova V, Čepičková M, Kobets T, Šíma M, Svobodová M, et al. Gene-Specific Sex Effects on Eosinophil Infiltration in Leishmaniasis. Biol Sex Differ (2016) 7:59. doi: 10.1186/s13293-016-0117-3
110. Bryson KJ, Millington OR, Mokgethi T, McGachy HA, Brombacher F, Alexander J. BALB/c Mice Deficient in CD4 T Cell IL-4ro Expression Control Leishmania Mexicana Load Although Female But Not Male Mice Develop a Healer Phenotype. PloS Negl Trop Dis (2011) 5(1):e930. doi: 10.1371/journal.pntd.0000930

111. Š́ma M, Havelková H, Quan L, Svobodová M, Jarošíková T, Vojtíšková J, et al. Genetic Control of Resistance to Trypanosoma Brucei Brucei Infection in Mice. PloS Negl Trop Dis (2011) 5:e1173. doi: 10.1371/journal.pntd.0001173

112. Carroll SF, Loredo Osti JC, Guillot L, Morgan K, Qureshi ST. Sex Differences in the Genetic Architecture of Susceptibility to Cryptococcus Neoformans Pulmonary Infection. Genes Immun (2008) 9:536-45. doi: 10.1038/ gene. 2008.48

113. Hayes KS, Hager R, Grencis RK. Sex-Dependent Genetic Effects on Immune Responses to a Parasitic Nematode. BMC Genomics (2014) 15:193. doi: 10.1186/1471-2164-15-193

114. Khramtsova EA, Davis LK, Stranger BE. The Role of Sex in the Genomics of Human Complex Traits. Nat Rev Genet (2019) 20(3):173-90. doi: 10.1038/ s41576-018-0083-1 Erratum in: Nat Rev Genet. 2019.

115. Dzamko NL. LRRK2 and the Immune System. Adv Neurobiol (2017) 14:12343. doi: 10.1007/978-3-319-49969-7_

116. Schuurhof A, Bont L, Siezen CL, Hodemaekers H, van Houwelingen HC, Kimman TG, et al. Interleukin-9 Polymorphism in Infants With Respiratory Syncytial Virus Infection: An Opposite Effect in Boys and Girls. Pediatr Pulmonol (2010) 45(6):608-13. doi: 10.1002/ppul.21229

117. Moretti S, Renga G, Oikonomou V, Galosi C, Pariano M, Iannitti RG, et al. A Mast Cell-ILC2-Th9 Pathway Promotes Lung Inflammation in Cystic Fibrosis. Nat Commun (2017) 8:14017. doi: 10.1038/ncomms14017

118. Pseudoautosomal Regions | HUGO Gene Nomenclature ... Par2. Available at: https://www.genenames.org/data/genegroup/\#!/group/716 (Accessed July 18, 2021).

119. Vermeesch JR, Petit P, Kermouni A, Renauld JC, Van Den Berghe H, Marynen P. The IL-9 Receptor Gene, Located in the Xq/Yq Pseudoautosomal Region, Has an Autosomal Origin, Escapes X Inactivation and Is Expressed From the Y. Hum Mol Genet (1997) 6(1):1-8. doi: 10.1093/hmg/6.1.1

120. Bhasin JM, Chakrabarti E, Peng DQ, Kulkarni A, Chen X, Smith JD. Sex Specific Gene Regulation and Expression QTLs in Mouse Macrophages From a Strain Intercross. PloS One (2008) 3:e1435. doi: 10.1371/journal.pone.0001435

121. Ober C, Loisel DA, Gilad Y. Sex-Specific Genetic Architecture of Human Disease. Nat Rev Genet (2008) 9:911-22. doi: 10.1038/nrg2415

Conflict of Interest: The authors declare that the research was conducted in the absence of any commercial or financial relationships that could be construed as a potential conflict of interest.

Publisher's Note: All claims expressed in this article are solely those of the authors and do not necessarily represent those of their affiliated organizations, or those of the publisher, the editors and the reviewers. Any product that may be evaluated in this article, or claim that may be made by its manufacturer, is not guaranteed or endorsed by the publisher.

Copyright (c) 2021 Lipoldová and Demant. This is an open-access article distributed under the terms of the Creative Commons Attribution License (CC BY). The use, distribution or reproduction in other forums is permitted, provided the original author(s) and the copyright owner(s) are credited and that the original publication in this journal is cited, in accordance with accepted academic practice. No use, distribution or reproduction is permitted which does not comply with these terms. 